\title{
c-Myc expression in human anagen hair follicles
}

C. Rumio, E. Donetti, A. Imberti, I. Barajon, E. Prosperi, ${ }^{*}$ M.F. Brivio,† A. Boselli,† E. Lavezzari, S. Veraldi, $\ddagger$ M. Bignotto and P. Castano

Institute of Human Anatomy, University of Milan, Via Mangiagalli 31, 20133 Milan, Italy

CNR Centre for Histochemistry Studies, Dept of Animal Biology, University of Pavia, Piazza Botta 10, 27100 Pavia, Italy

†Department of Structural and Functional Biology, University of Insubria, Via Durant 3, 21100 Varese, Italy

¥Department of Dermatology, University of Milan, Via Pace 9, 20100 Milan, Italy

Correspondence: Prof. Paolo Castano, Istituto di Anatomia Umana, Università di Milano, Via Mangiagalli 31, 20133 Milano, Italy. E-mail: paolo.castano@unimi.it

\section{KEYWORDS}

apoptosis $\bullet \mathrm{c}-\mathrm{Myc} \cdot$ hair follicle $\cdot$ scalp $\bullet$ terminal differentiation

\section{ABSTRACT}

The hair follicle represents a very attractive organ system for studying the precise balance between cell proliferation, growth, differentiation, and death of cells, because it periodically and regularly regenerates, retaining its morphogenetic signals throughout its life. One of the most intriguing oncogenes which is able to induce both cell growth and apoptosis, depending upon the environmental conditions, is c-myc. The aim of the present study was to investigate its presence and localization in human hair follicles by immunohistochemistry and immunofluorescence. Our observations demonstrated the consistent presence of two clusters of cMyc-expressing cells in anagen follicles, located in two annular regions of the inner root sheath, at the border between cells characterized by putative trichohyalin granules and cells which are keratinized. The lower group belongs to Henle's layer, while the upper group belongs to Huxley's layer. cMyc oncoprotein seems to favour apoptosis/differentiation and may be a marker for terminal differentiation of trichocytes, at least in the inner root sheath. Our findings agree with the interpretation that the complex morphology of the hair follicle reflects its complex function; the extrusion of a highly organized multicellular structure, the hair shaft, driven by another highly organized multicellular structure, the inner root sheath. 
The development and homeostasis of multicellular organisms and their tissues and organs requires a precise balance between cell proliferation, growth, differentiation and death. The skin and its adnexa provide a particularly interesting model for studying these phenomena, as this tissue undergoes continuous renewal and remodelling throughout life. The hair follicle is the only organ system which periodically and regularly regenerates throughout mammalian adulthood, i.e. it is an organ that retains its morphogenetic signals throughout its life. Some authors have demonstrated a key role of apoptosis in normal and pathological skin, even though in some instances the exact nature of this phenomenon appears controversial. ${ }^{1,2}$ In fact, while some authors do not consider the terminal differentiation of keratinocytes as an apoptotic phenomenon, others interpret this differentiation as a specialized form of apoptosis.

Numerous studies have demonstrated that cell growth, proliferation and apoptosis may be closely linked and modulated by sets of oncogenes, which can either induce cells to initiate apoptosis, or alternatively block apoptosis and stimulate proliferation. ${ }^{3}$ Furthermore, oncogenes exist which are able to induce both cell growth and apoptosis, depending upon environmental conditions. ${ }^{4}$ One of the most intriguing examples of such a multipotential gene is c-myc. ${ }^{5-9}$ The protein encoded for by this gene is able to promote either cell growth, in the presence of growth/survival factors, ${ }^{5}$ or programmed cell death in the absence of the same factors.

Few studies have been carried out to identify the presence of c-Myc in skin components; the presence of c-Myc expression has been reported in vivo and in vitro in normal and pathological epidermal keratinocytes. ${ }^{10-14}$ Seiberg et al. ${ }^{15}$ studied the expression of different regulating genes in total skin extracts of mice and suggested variations in the transcription levels of c-myc in relation to the hair follicle cycle. However, a specific localization of c-Myc to the hair follicle was not demonstrated and in a recent comprehensive list of molecules implicated in the control of follicle morphogenesis, hair cycling and differentiation, there is no reference to c-Myc.

The aim of our study was to evaluate, by means of immunocytochemical and immunofluorescence methods, the localization of c-Myc in human normal scalp and particularly in the hair follicle, because this is the only structure in the human body which demonstrates throughout its life cell proliferation, growth, differentiation and apoptosis. 


\section{Materials and methods}

Hair follicle samples were obtained from the scalps of 14 male individuals undergoing microislet (one to two hair follicles each) homograft operations. All patients gave informed consent. We observed 60 hair follicles from the occipital region of the scalp. Surgical samples were immersed in polyethylene-glycol, frozen with liquid nitrogen and preserved at $-80{ }^{\circ} \mathrm{C}$, for a maximum of 30 days before use. The microislets were longitudinally sectioned with a cryostat and the sections, 10-20 $\mu \mathrm{m}$ thick, were evaluated by immunohistochemistry and immunofluorescence for the presence of cMyc oncoprotein. Some sections were fixed either with methanol/acetone or paraformaldehyde before the reaction. We used a monoclonal c-Myc antibody cl. 9E10 against human P67 protein (Santa Cruz Biotechnology Inc., Santa Cruz, CA, U.S.A.). The antibody was tested by Western blotting as a specificity control. 5-bromodeoxyuridine (BrdU) incorporation was used to identify S-phase cells and the terminal deoxynucleotidyl transferasemediated deoxyuridine triphosphate nick end labelling (TUNEL) technique to identify apoptotic cells. Sections were observed with a Zeiss Axioplan fluorescence microscope with fluorescein isothiocyanate (FITC) and 5-(4,6dichlorotriazinyl)-aminofluorescein (DTAF), tetramethyl rhodamine isothiocyanate and Texas Red filters.

\section{Sodium dodecyl sulphate-polyacrylamide gel electrophoresis and immunoblotting}

Hair follicles were isolated from fragments of human scalp maintained for $1 \mathrm{~h}$ in William E medium (Sigma, St Louis, MO, U.S.A.). After incubation in a balanced salt solution ( $\mathrm{pH} 7 \cdot 2$ ), containing $20 \mathrm{mmol} \mathrm{L}^{-1}$ ethylenediamine tetraacetic acid, for $2 \mathrm{~h}$ at $37^{\circ} \mathrm{C}$ while stirring every $15 \mathrm{~min}$, the follicles were gently pulled out from the epidermis with small tweezers and, after washing in phosphate-buffered saline (PBS), they were frozen in liquid nitrogen. Thirty follicles were denatured in $300 \mathrm{~mL}$ of sample buffer ${ }^{17}$ at $100{ }^{\circ} \mathrm{C}$ for 15 min. Protein samples were loaded on to $10 \%$ acrylamide gels and run overnight at $50 \mathrm{~V}$ (constant voltage). Sodium dodecyl sulphatepolyacrylamide gel electrophoresis (SDS-PAGE) samples were transferred on to nitrocellulose sheets at $125 \mathrm{~mA}$ for $15 \mathrm{~h}$ for Western blotting. ${ }^{18} \mathrm{c}-\mathrm{Myc}$ gene products were localized by means of the anti-c-Myc antibody $1: 400$ in Tris-buffered saline-bovine serum albumin, for $1 \mathrm{~h}$ at $20^{\circ} \mathrm{C}$. An alkaline phosphatase-conjugated antimouse IgG (Sigma) $1: 5000$ was used as the secondary antibody. As a control the first antibody was omitted.

\section{Immunocytochemistry}

The sections were treated with $\mathrm{H}_{2} \mathrm{O}_{2} 0.3 \%$ in PBS, incubated with rabbit serum 1:10 (Dako A/S, Glostrup, Denmark) for $20 \mathrm{~min}$ at room 
temperature, then with anti-c-Myc primary antibody $1: 50$ for $1 \mathrm{~h}$ at $37^{\circ} \mathrm{C}$. After incubation with rabbit antimouse lgG antibody $1: 25$ (Dako A/S) for $1 \mathrm{~h}$ at $37^{\circ} \mathrm{C}$, the sections were incubated with mouse peroxidase antiperoxidase (PAP) 1:50 (Dako A/S) for $90 \mathrm{~min}$ at $37^{\circ} \mathrm{C}$, developed with diaminobenzidine (Sigma), washed, air dried and mounted with Entellan (Merck, Darmstadt, Germany). Controls consisted of reactions with the chromogen substrate (diaminobenzidine) alone, omitting the primary antibody, omitting the secondary antibody and omitting the PAP complex.

\section{Immunofluorescence}

Longitudinal scalp sections were incubated with goat serum 1:10 (Dako $\mathrm{A} / \mathrm{S}$ ), then with anti-c-Myc primary antibody $1: 50$ for $1 \mathrm{~h}$ at $37^{\circ} \mathrm{C}$ in a humid chamber. After washing, they were incubated with secondary goat antimouse antibody $1: 150$ for $1 \mathrm{~h}$ at $37^{\circ} \mathrm{C}$ labelled with FITC or Texas Red (Jackson Immunoresearch Laboratories Inc., West Grove, PA, U.S.A.). The sections were mounted with Vectashield antifading medium (Vector Laboratories Inc., Burlingame, CA, U.S.A.). As a control, the primary antibody was omitted.

\section{5-bromodeoxyuridine (BrdU) incorporation and BrdU/c-Myc double fluorescence}

The technique described by Gratzner ${ }^{19}$ was adapted for use with our samples. The microislets were immediately incubated with BrdU $400 \mu \mathrm{mol} \mathrm{L}{ }^{-1}$ in William E Medium (Sigma) and fetal calf serum (Sigma) 10\% at $37{ }^{\circ} \mathrm{C}$ for $3 \mathrm{~h}$. They were then frozen with liquid nitrogen and sectioned with a cryostat at $10-15 \mu \mathrm{m}$ thickness. The DNA was denatured with $2 \mathrm{~mol} \mathrm{~L}^{-1} \mathrm{HCl}$ for $30 \mathrm{~min}$ at room temperature, and then the acidity was neutralized with $\mathrm{Na}_{2} \mathrm{~B}_{4} \mathrm{O}_{7} \quad 0.1 \mathrm{~mol} \mathrm{~L}^{-1}$ for 5-10 min. The sections were incubated with primary monoclonal anti-BrdU antibody (Becton Dickinson Italia SpA, Milano, Italy) $1: 100$ at room temperature for 45 min, then with a secondary donkey antimouse Texas Red-conjugated antibody (Jackson Immunoresearch Laboratories) $1: 100$ in a humid chamber at $37^{\circ} \mathrm{C}$ for $1 \mathrm{~h}$. After washing, they were incubated with primary mouse antihuman c-Myc antibody $1: 50$ for $1 \mathrm{~h}$ at $37^{\circ} \mathrm{C}$, washed and incubated with secondary donkey antimouse DTAF-conjugated antibody (Jackson Immunoresearch Laboratories) $1: 50$ for $1 \mathrm{~h}$ at $37^{\circ} \mathrm{C}$. The sections were mounted with Vectashield antifading medium (Vector Laboratories Inc.).

\section{Terminal deoxynucleotidyl transferase-mediated deoxyuridine triphosphate nick end labelling}

The TUNEL method, as described by Gavrieli et al. ${ }^{20}$ was performed on sections previously processed for C-Myc immunofluorescence. Briefly, terminal deoxyribonucleotidyl-transferase (Boehringer Mannheim, Mannheim, Germany) was used to insert FITC-conjugated nucleotides 
(Boehringer Mannheim) at the 3' ends of the DNA fragments. After washing, the sections were mounted with Vectashield antifading medium (Vector Laboratories Inc.). As the negative control we omitted the terminal transferase enzyme from the nucleotide mixture.

\section{Results}

In our samples, c-Myc oncoprotein had a predominantly cytoplasmic distribution while nuclei were only occasionally labelled ( Figs 1-3) . Postfixation of cryostat sections either with methanol/acetone or paraformaldehyde did not affect the distribution of the immunoreactivity. Control experiments were negative. The results of the present study refer to anagen follicles (steps IV-VI). The inner root sheath (IRS) of the hair follicle was the only skin structure where c-Myc reactivity could be observed. The other components of the hair follicle, epidermis, skin adnexa and dermal cells showed no labelling.

Figure 1. Double fluorescence image of a hair follicle at the level of the lower ring. cMyc-positive cells have red cytoplasm while terminal deoxynucleotidyl transferase-mediated deoxyuridine triphosphate nick end labelling (TUNEL)positive cells have yellow/green nuclei. TUNEL-positive cells are numerous at the same level as the LR cells but only a few (arrows) show double labelling. Bar: $25 \mu \mathrm{m}$.

[Normal View ]

Figure 2. Double fluorescence image of a hair follicle at the level of the c-myc positive upper ring: c-Myc-positive cells have red cytoplasm (Texas Red) while terminal deoxynucleotidyl transferasemediated deoxyuridine triphosphate nick end labelling (TUNEL)-positive cells have yellow/green nuclei (dichlorotriazinylfluorescein) . Some upper ring cells show double labelling. Bar: $25 \mu \mathrm{m}$.

[Normal View ] 
Figure 3. Immunofluorescence image of the c-Myc positive upper ring in a longitudinal section of a hair follicle tangential to the Huxley's layer. c-Mycpositive cells are numerous and show clear cytoplasmic labelling. Arrows: unlabelled nuclei. Bar: $25 \mu \mathrm{m}$.

[Normal View ]

When analysed by SDS-PAGE, follicles showed a reproducible pattern of protein bands ranging from 20 to $200 \mathrm{kDa}$. Five major components were detectable in the region of $40-70 \mathrm{kDa}$ ( Fig. 4, lanes A and B). C-Myc immunoblotting of the same samples revealed a positive band corresponding to p67 protein ( Fig. 4, lanes C and D), confirming that in the follicle total protein extracts, the monoclonal antibody against c-Myc labelled only p67 protein. As a second faint band was observable, we cannot exclude the possibility that the antibody cross-reacts with both the phosphorylated and unphosphorylated forms of the protein that comigrate with the main components in the $60-70 \mathrm{kDa}$ zone. Controls omitting the primary antibody were negative. In the IRS, c-Myc immunoreactivity was clearly visible in Huxley's and Henle's layers and was constantly located in two annular regions. The distance between the two rings varied according to the length of the hair follicle.

Figure 4. Sodium dodecyl sulphatepolyacrylamide gel electrophoresis and immunoblotting of proteins extracted from hair follicles. Lanes A and B: 7 and $15 \mu \mathrm{L}$ of loaded sample. Lanes $C$ and $D$ : immunoblot of the samples run in lanes A and $B$, labelled with anti-c-Myc monoclonal antibody. Arrowhead indicates positive bands of about $67 \mathrm{kDa}$. Lane S: molecular weights standard.

[Normal View ]

The first group of labelled cells ( $\mathrm{LR}=$ lower ring) was located at the neck of the follicle (i.e. where it contracts to become cylindrical; Fig. 5) . The LR has a height of two to five cells which are elongated. They clearly belong to Henle's layer of the IRS ( Fig. 6) . Below the LR, Henle's layer cells contain granules (probably trichohyalin granules) and clusters of filaments, while above the LR the cells are without granules and appear homogeneously keratinized. Some c-Myc-positive cells were also labelled by the TUNEL reaction, indicating that their DNA was fragmented ( Fig. 1). The second 
group of labelled cells (UR = upper ring) was located in the isthmus, at the level of the keratogenic zone of the upper third of the lower follicle ( Figs 7 and 8). c-Myc expression extended to a height of seven to ten cells ( Figs 3 and 7), which appeared flattened. They belong to Huxley's layer and mark a border between cells characterized by granules (probably trichohyalin granules) and those without granules ( Fig. 8). UR cells seem to be free from granules, and some of them are labelled by the TUNEL method ( Fig. 2). The localization of the UR frequently corresponds to the point where the hair shaft separates from the IRS. Labelled cells often showed filaments resembling the keratin filaments observable with conventional light microscopy, but never had tricohyalin-like granules.

Figure 5. Inner portion of the hair follicle under phase contrast (a) and visualized by immunofluorescence with anti-c-Myc antibody (b). c-Myc labelled cells (b) form a ring (lower ring cells at the neck of the bulb: asterisk in a), height two to five cells, which has been cut tangential to Henle's layer. Bars: $\mathbf{5 0}$ um.

[Normal View ]

Figure 6. c-Myc immunostaining of the lower ring cells of a longitudinally sectioned follicle (haematoxylin/eosin counterstain). The dark labelled cells clearly belong to Henle's layer (HE) and separate the deeper cells with stained cytoplasmic filaments from the upper ones without any such staining. The cells of Huxley's (HU) layer are evident, with their trichohyalin granules. ORS: outer root sheath; HS: hair shaft. Bar: $25 \mu \mathrm{m}$. [Normal View ]

Figure 7. Immunofluorescence image of two longitudinally sectioned hair follicles. c-Myc labelling identifies two annular clusters of cells at the level of the neck of the bulb (lower ring = LR) and of the upper third of the follicle (upper ring = UR). The image has been printed so that the follicle 
silhouette is faintly visible. Sg: sweat glands; bar $100 \mu \mathrm{m}$.

[Normal View ]

Figure 8. Double exposure of an immunofluorescence and phase contrast image at the level of the c-Myc-positive upper ring (UR). The section is tangential to Huxley's layer (HU) so that the UR seems to comprise a low number of cMyc-positive cells. The image clearly shows that the UR (stained red) forms a border between the deeper cells of Huxley's layer, rich with putative trichohyalin granules (TR) and the upper keratinized cells (KE). HE: Henle's layer; ORS: outer root sheath. Bar: $25 \mu \mathrm{m}$.

[Normal View ]

c-Myc labelled cells were not actively proliferating, as incorporation of the thymidine analogue BrdU in their DNA was never observed ( Fig. 9) . On the other hand, in the same samples, actively proliferating cells were located in the matrix and in the outer root sheath (ORS), in the basal layer of sebaceous glands, in the basal layer and the first level of the spinous layer of epidermis and infundibulum. The IRS cells never incorporated BrdU.

Figure 9. Double fluorescence image for the proliferation marker 5bromodeoxyuridine (BrdU) (red) and for cMyc (green). The BrdU-positive cells (Sphase), with red nuclei, are only localized in the matrix (M) and in the outer root sheath, while neither lower ring (LR) nor upper ring (UR) cells are BrdU positive. Bar: $100 \mu \mathrm{m}$. [Normal View ]

\section{Discussion}

In the present study, c-Myc immunoreactivity could be observed only in a specific region of the hair follicle, the IRS. The lack of c-Myc in the epidermis, where it could have been expected according to previous studies, 
might be attributed to methodological reasons. In fact, in most of the previous studies the presence of c-myc activation was evaluated through its mRNA, either by extractive methods or in situ hybridization, which might not correspond to a level of protein expression detectable by immunohistochemistry.

c-Myc is a nuclear protein which is generally associated with the nuclear matrix; ${ }^{21-23}$ however, in our samples c-Myc immunoreactivity appeared mostly confined to the cytoplasm even though, occasionally, positive nuclei could be observed. Cytoplasmic localization of c-Myc has been attributed by some authors to the methods used for tissue fixation and processing. ${ }^{24,25}$ There are no indications that this could be the case in our study because fixation either with methanol-acetone or paraformaldehyde did not change the pattern of the immunoreactivity. On the other hand, in vivo and in vitro intracellular translocation of c-Myc as well as that of other proto-oncogenes appears to be correlated to the switch from the proliferative to the differentiating pathway. ${ }^{26-33}$ In this context, the shift of c-Myc from the nucleus to the cytoplasm could be interpreted as the sign of the end of its action of transactivation on genes involved in cell proliferation. Our finding of a predominantly cytoplasmic distribution of c-Myc in a highly organized differentiating layer of the hair follicle in two constant and specific regions, is in line with this hypothesis.

The absence of detectable c-Myc expression in other hair follicle structures undergoing terminal differentiation seems to suggest the presence of layerspecific mechanisms of differentiation possibly involving different factors. In the IRS, the differentiation takes place in Henle's and Huxley's layers at different levels. IRS cells do not show any proliferative activity, indicating that they are simply pushed forward by the actively proliferating matrix, and proceed through terminal differentiation along the direction of growth of the follicle. ${ }^{34}$

One of the landmarks of the terminal differentiation of the IRS keratinocytes is the disappearance of trichohyalin granules and the formation of a hard shell. ${ }^{35}$ The localization of c-Myc immunoreactivity, found in the present study, seems to coincide with the regions where putative trichohyalin granules are no longer visible.

This observation, together with the different localization of the lower and upper c-Myc-positive rings in accordance with the respective differentiation levels in Henle's and Huxley's layers and the observation of TUNEL positivity in c-Myc labelled cells, which is consistent with nuclear fragmentation observed after trichohyalin granules disappearance, ${ }^{36}$ strongly suggest that $\mathrm{c}-\mathrm{Myc}$ is involved in the terminal differentiation 
processes of the hair follicle, namely of the IRS.

c-Myc oncoprotein could exert a pro-apoptotic/differentiation influence, in agreement with the data of Dotto et al. ${ }^{10}$ in terminally differentiating keratinocytes. The presence of TUNEL positive elements, possibly undergoing apoptosis, during the anagen phase is also in agreement with the recent study by Lindner et al. ${ }^{37}$ and Soma et al. ${ }^{38}$ reporting that, in mouse and humans, clusters of apoptotic cells appear during the anagen phase, i.e. before follicle regression. In our opinion, c-Myc could be a useful marker for recognition of the last steps of the terminal differentiation of trichocytes, at least in the IRS.

\section{References}

1 Polakowska RR, Piacentini M, Bartlett R et al. Apoptosis in human skin development: morphogenesis, periderm and stem cells. Dev Dynamics 1994; 199: 17688.

2 Paus R, Rosenbach T, Haas N, Czarnetzki BM. Patterns of cell death: the significance of apoptosis for dermatology. Exp Dermatol 1993; 2: 311.

3 Harrington EA, Bennett MR, Fanidi A, Evan Gl. c-Myc induced apoptosis in fibroblasts is inhibited by specific cytokines. EMBO J 1994; 13: 328695.

4 Evan GI, Brown L, Whyte M, Harrington E. Apoptosis and the cell cycle. Curr Opin Cell Biol 1995; 7: 82534.

5 Evan GI, Wyllie AH, Gilberg CS. Induction of apoptosis in fibroblasts by cMyc protein. Cell 1992; 69: 11928.

6 Askew DS, Ashmun RA, Simmons BC, Cleveland JL. Constitutive c-Myc expression in an IL-3 dependent myeloid cell line suppresses cell cycle arrest and accelerates apoptosis. Oncogene 1992; 6: 191522.

7 Shi Y, Glynn JM, Guilbert LJ et al. Role for c-Myc in activation-induced apoptotic cell death in T cell hybridomas. Science 1992; 257: 21214.

8 Desbarats L, Schneider A, Muller D et al. Myc: a single gene controls both proliferation and apoptosis in mammalian cells. Experientia 1996; 52: 1123 9.

9 Stenn KS, Lawrence L, Veis D et al. Expression of the bcl-2 protooncogene in the cycling adult mouse hair follicle. J Invest Dermatol 1994; 103: 10711 .

10 Dotto GP, Gilma MZ, Maruyama M, Weinberg RA. c-Myc and c-fos expression in differentiating primary keratinocytes. EMBO $J$ 1986; 5: 2853 7.

11 Sutton R, Cam GR, Ward WG. Myc proto-oncogenes of wool and hair growth. Ann NY Acad Sci 1991; 642: 32638.

12 Elder JT, Tavakkol A, Klein SB et al. Protooncogene expression in normal and psoriatic skin. J Invest Dermatol 1990; 94: 1925.

13 Ogiso $\mathrm{Y}$, Oikawa $\mathrm{T}$, Kondo $\mathrm{N}$ et al. Expression of proto-oncogenes in 
normal and tumor tissues of human skin. J Invest Dermatol 1988; 90: 8414. 14 Hurlin PJ, Foley KP, Ayer DE et al. Regulation of Myc and Mad during epidermal differentiation and HPV-associated tumorigenesis. Oncogene 1995; 11: 2487501.

15 Seiberg M, Marthinuss J, Stenn KS. Changes in expression of apoptosisassociated genes in skin mark early catagen. J Invest Dermatol 1995; 104: 7882.

16 Stenn KS, Combates NJ, Eilertsen KJ et al. Hair follicle growth controls. Dermatol Clin 1996; 14: 54358.

17 Laemli UK. Cleavage of structural proteins during the assembly of the head of bacteriophage T4. Nature 1970; 227: 6805.

18 Towbin H, Staehlin T, Gordon J. Electrophoretic transfer of proteins from polyacrylamide gels to nitrocellulose sheets: procedure and some applications. Proc Natl Acad Sci USA 1979; 76: 43504.

19 Gratzner HG. Monoclonal antibody to 5-bromo- and 5-iododeoxyuridine: a new reagent for detection of DNA replication. Science 1982; 218: 4745.

20 Gavrieli Y, Sherman Y, Ben Sasson SA. Identification of programmed cell death in situ via specific labelling of nuclear DNA fragmentation. $J$ Cell Biol 1992; 119: 493501.

21 Eisenman RN, Tachibana CY, Abrams HD, Hann SR. v-myc and c-Mycencoded proteins are associated with the nuclear matrix. Mol Cell Biol 1985; 5: 11426.

22 Evan GI \& Hancock D. Studies of the interaction of the human c-Myc protein with cell nuclei: p62 c-Myc as a member of a discrete subset of nuclear proteins. Cell 1985; 43: 25361.

23 DePinho RA, Schreiber-Agus N, Alt FW. Myc family oncogenes in the development of normal and neoplastic cells. Adv Cancer Res 1991; 57: 1 46.

24 Yamaguchi A, Ninomiya I, Ishida T et al. Immunohistochemical detection of c-Myc products in colorectal cancer and proliferative cell rate. Oncology 1992; 49: 404.

25 Jones DJ, Ghosh AK, Moore $M$ et al. A critical appraisal of the immunohistochemical detection of the c-Myc oncogene product in colorectal cancer. Br J Cancer 1987; 56: 77983.

26 Craig RW, Buchan HL, Civin C, Kastan MB. Altered cytoplasmic/nuclear distribution of the c-Myc protein in differentiation ML-1 human myeloid leukemia cells. Cell Growth Differ 1993; 4: 34957.

27 Wakamatsu $Y$, Watanabe $Y$, Shimono A, Kondoh $H$. Transition of localization of the N-Myc protein from nucleus to cytoplasm in differentiating neurons. Neuron 1993; 10: 19.

28 Lemaitre J-M, Bocquet S, Buckle R, Mechali M. Selective and rapid nuclear translocation of a c-Myc-containing complex after fertilisation of Xenopus leavis eggs. Mol Cell Biol 1995; 15: 505462.

29 Taylor MV, Gusse M, Evan Gl et al. Xenopus myc proto-oncogene during 
development: expression as a stable maternal mRNA uncoupled from cell division. EMBO J 1986; 5: 356370.

30 Gusse M, Ghysdael J, Evan G et al. Translocation of a store of maternal cytoplasmic c-Myc protein into nuclei during early development. Mol Cell Biol 1989; 9: 5395403.

31 Meichle A, Philipp A, Eilers M. The functions of Myc proteins. Biochim Biophys Acta 1992; 1114: 12946.

32 Wang $Y$, Toury R, Hauchecorne $M$ et al. Expression and subcellular localization of the Myc superfamily proteins: C-Myc, Max, Mad1 and Mx1 in the epiphyseal plate cartilage chondrocytes of growing rats. Cell Mol Biol 1997; 43: 17588.

33 Vriz S, Lemaitre JM, Leibovici $M$ et al. Comparative analysis of the intracellular localization of c-Myc, c-Fos and replicative proteins during cell cycle progression. Mol Cell Biol 1992; 12: 354855.

34 Ito $\mathrm{M}$, Tazawa $\mathrm{T}$, Shimizu $\mathrm{N}$ et al. Cell differentiation in human anagen hair and hair follicles studied with anti-hair keratin monoclonal antibodies. $J$ Invest Dermatol 1986; 86: 5639.

35 Manabe M \& O'Guin WM. Keratohyalin, trichohyalin and keratohyalintrichohyalin hybrid granules: an overview. J Dermatol 1992; 19: 74955.

36 Breathnach AS. An Atlas of the Ultrastructure of Human Skin. London: Churchill Livingstone, 1971.

37 Lindner G, Botchkarev VA, Botchkareva NV et al. Analysis of apoptosis during hair follicle regression (catagen). Am J Pathol 1997; 151: 160117.

38 Soma T, Ogo M, Suzuki J et al. Analysis of apoptotic cell death in human hair follicles in vivo and in vitro. J Invest Dermatol 1998; 111: 94854. 